\title{
Stress induced urinary incontinence in patients with spinocerebellar degeneration
}

\author{
Ryuji Sakakibara, Takamichi Hattori, Kohei Kita, Kimihito Arai, Tomonori Yamanishi, \\ Kosaku Yasuda
}

\begin{abstract}
Objectives-To examine the pathophysiology of "stress induced urinary incontinence" (urinary incontinence evoked by abdominal straining) in patients with spinocerebellar degeneration.

Methods-Micturitional symptoms of 184 patients with spinocerebellar degeneration who were admitted to hospital were studied repeatedly. Urodynamic studies were made in symptomatic patients, and consisted of uroflowmetry, measurement of residual urine, urethral pressure profilometry, medium fill water cystometry, and external sphincter EMG

Results-Twenty nine $(\mathbf{1 5 . 8 \% )}$ patients with spinocerebellar degeneration showed stress induced urinary incontinence. Twenty of the 29 patients had detrusor overactivity, low compliance detrusor, or residual urine, resembling urgency and overflow types of incontinence (complicated form). The other nine had none of these findings (pure form), but showed decreased maximum urethral closure pressure in four, absence of bulbocavernosus reflex in two, absence of voluntary sphincter contraction in one, incompetent urinary storage even at the first sensation in two, and high amplitude and polyphasic neurogenic changes in three of five patients studied, indicative of neurogenic sphincter dysfunction.
\end{abstract}

Conclusions-Stress induced urinary incontinence in spinocerebellar degeneration had various underlying mechanisms. Some of the patients only showed evidence of pudendal denervation, which can cause external sphincter weakness and may reflect lesions of the sacral Onuf's nucleus and the pudendal nerve. Urodynamic studies are necessary to evaluate stress induced urinary incontinence in patients with spinocerebellar degeneration, to prescribe appropriate therapies.

(F Neurol Neurosurg Psychiatry 1998;64:389-391)

Keywords: spinocerebellar degeneration; multiple system atrophy; stress induced urinary incontinence; urodynamics; pudendal nerve
Urinary incontinence evoked by abdominal stress (straining) includes a variety of different underlying abnormalities. Genuine stress incontinence is the most common, and affects most women with incontinence. ${ }^{12}$ The principal mechanism of genuine stress incontinence is an incomplete transmission of abdominal pressure to the proximal urethra, due to an anatomical descent of the urethrovesical junction. ${ }^{1}$ Pelvic floor weakness causes the dysfunction, which is often the result of aging and delivery injury ${ }^{3}$ and seldom of neural aetiology. ${ }^{4}$ In neurological diseases, abdominal straining also provokes detrusor overactivity as in the urge type of incontinence, or causes leakage of postvoid residual urine as in the overflow type of incontinence. These cases of "stress induced urinary incontinence" need careful urodynamic assessment. Urinary incontinence is a common urethrovesical symptom in patients with spinocerebellar degeneration, ${ }^{5-7}$ particularly in those with multiple system atrophy. ${ }^{89}$ However, stress induced urinary incontinence of patients with spinocerebellar degeneration is not fully understood. We here describe our findings on the stress induced urinary incontinence in spinocerebellar degeneration and the urodynamic studies carried out.

\section{Materials and methods}

This is a retrospective study in which we reviewed the records of 184 patients with spinocerebellar degeneration, all of whom were admitted to our hospital and satisfied the criteria of the Research Committee of Ataxic Diseases in the Ministry of Health and Welfare

Table 1 Stress induced urinary incontinence in patients with SCD

\begin{tabular}{ll}
\hline$S C D$ & $n(\%)$ \\
\hline Total & $29 / 184(15.8)$ \\
Male (n (\%)) & $7 / 108(6.5)$ \\
Female (n (\%)) & $22 / 76(28.9)$ \\
Age (y), mean (range) & $57(18$ to 78$)$ \\
Non-hereditary SCD (n (\%)) & \\
$\quad$ Multiple system atrophy & $24 / 133(18)$ \\
Other non-hereditary SCD & $2 / 11(18.2)$ \\
Hereditary SCD (n (\%)) & \\
$\quad$ Machado-Joseph disease & $2 / 18(11.1)$ \\
$\quad$ Dentatorubropallidoluysian atrophy & $1 / 5(20)$ \\
$\quad$ Hereditary cortical cerebellar atrophy & $0 / 5(0)$ \\
$\quad$ Other hereditary SCD & $0 / 12(0)$
\end{tabular}

SCD = spinocerebellar degeneration. 
Table 2 Patients with a pure form of stress induced urinary incontinence

\begin{tabular}{|c|c|c|c|c|c|c|c|c|c|c|c|c|c|c|}
\hline $\begin{array}{l}\text { Patient } \\
\text { No }\end{array}$ & $\begin{array}{l}\text { Age } \\
(y)\end{array}$ & Sex & $\begin{array}{l}\text { Duration } \\
(y)\end{array}$ & Diagnosis & $\begin{array}{l}\text { Residual } \\
\text { urine }\end{array}$ & $\begin{array}{l}\text { Upmax } \\
\left(\mathrm{cm} \mathrm{H} \mathrm{H}_{2} \mathrm{O}\right)\end{array}$ & $F D V(m l)$ & $\begin{array}{l}M D V \\
(m l)\end{array}$ & $\begin{array}{l}\text { Detrusor } \\
\text { overactivity }\end{array}$ & $\begin{array}{l}\text { Low } \\
\text { compliance }\end{array}$ & $\begin{array}{l}\text { Absence } \\
\text { of BCR }\end{array}$ & $\begin{array}{l}\text { Absence } \\
\text { of VSC }\end{array}$ & $\begin{array}{l}\text { Unrelaxing } \\
\text { sphincter }\end{array}$ & $\begin{array}{l}\text { Neurogenic } \\
\text { change }\end{array}$ \\
\hline 1 & 18 & $\mathrm{~F}$ & 3 & $\begin{array}{l}\text { Machado } \\
\text {-Joseph }\end{array}$ & - & $12 \downarrow$ & $\begin{array}{l}180 \text { (incompetent } \\
\text { storage) }\end{array}$ & Stop & - & - & + & - & - & + \\
\hline 2 & 33 & $\mathrm{~F}$ & 6 & DRPLA & - & $35 \downarrow$ & $>700 \uparrow$ & & - & - & & & - & \\
\hline 3 & 44 & $\mathrm{~F}$ & 3 & OPCA & - & 54 & $>600 \uparrow$ & & - & - & - & & - & \\
\hline 4 & 49 & $\mathrm{~F}$ & 2 & OPCA & - & 47 & 170 & 340 & - & - & - & - & - & \\
\hline 5 & 61 & $\mathrm{~F}$ & 6 & OPCA & - & $34 \downarrow$ & 200 & 500 & - & - & - & - & + & \\
\hline 6 & 62 & $\mathrm{~F}$ & 4 & OPCA & - & 68 & 200 & 550 & - & - & - & - & - & + \\
\hline 7 & 64 & $\mathrm{~F}$ & 1 & OPCA & - & 46 & 180 & 310 & - & - & - & - & - & - \\
\hline 8 & 70 & $\mathrm{~F}$ & 10 & LCCA & - & 55 & $350 \uparrow$ & 550 & - & - & - & - & - & - \\
\hline 9 & 70 & $\mathrm{~F}$ & 8 & OPCA & - & $30 \downarrow$ & $\begin{array}{l}250 \text { (incompetent } \\
\text { storage) }\end{array}$ & Stop & - & - & + & + & + & + \\
\hline
\end{tabular}

Duration=duration of disease; DRPLA=dentatorubropallidoluysian atrophy; OPCA=olivopontocerebellar atrophy; LCCA=late cortical cerebellar atrophy; Upmax= maximum urethral closure pressure; FDV=first desire to void; $\mathrm{MDV}=$ maximum desire to void; $\mathrm{BCR}=$ bulbocavernosus reflex; VSC=voluntary sphincter contraction.

of Japan. ${ }^{10}$ One hundred and eight were male and 76 were female, mean age 55, range 15-78 years. Micturitional symptoms were studied and neurological examinations were made repeatedly. The symptoms consisted of nocturnal or diurnal urinary frequency, sensation of urgency, urinary incontinence, and enuresis, difficulty in voiding (including urinary hesitation and prolongation), and urinary retention. Patients with urinary symptoms did not have an apparent urinary tract infection. None of the male patients studied had apparent prostatic hypertrophy on rectal digital examination and ultrasonography. Urodynamic studies consisted of uroflowmetry, measurement of residual urine, urethral pressure profilometry, medium fill water cystometry, and external sphincter EMG. Uroflow curves were evaluated according to Siroky's nomogram. ${ }^{11}$ The normal range of urodynamic indices were residual urine volume $<30 \mathrm{ml}$; maximum urethral closure pressure (UPmax) $>41 \mathrm{~cm}$ $\mathrm{H}_{2} \mathrm{O}$ and $<82 \mathrm{~cm} \mathrm{H}_{2} \mathrm{O}$; first desire to void (FDV) $>100 \mathrm{ml}$ but $<300 \mathrm{ml}$ and maximum desire to void (MDV) $>200 \mathrm{ml}$ but $<600 \mathrm{ml}$. Increased FDV or MDV indicates disturbed bladder sensation. The methods and definitions used for the urodynamic studies conformed to the standards proposed by the International Continence Society. ${ }^{12}$ Informed consent was obtained from all the patients before the urodynamic studies were made.

\section{Results}

Accurate history taking showed that 29 $(15.8 \%)$ of 184 patients with spinocerebellar degeneration had stress induced urinary incontinence (table 1). Twenty three of 29 patients had urinary symptoms other than stress induced incontinence-namely, difficulty of voiding (23), nocturnal urinary frequency (21), diurnal urinary frequency (14), urinary urgency (20), urge incontinence (10), enuresis (seven), transient urinary retention (two), and overflow incontinence (one). The micturitional symptoms started with or after the occurrence of the diseases, and deteriorated gradually along with the other neurological signs.

Urodynamic studies were made in the patients with stress induced urinary incontinence. Uroflowmetry was performed on 17 patients, 12 of whom had decreased maximum and mean uroflow rates. Residual urinary volume was measured for all the patients; residual urine $>30 \mathrm{ml}$ was noted in 18 , mean volume $178 \mathrm{ml}$, range $38-760 \mathrm{ml}$. Water cystometry was performed on all the patients: bladder volume at FDV or MDV was increased in six, three of whom had FDV $>600 \mathrm{ml}$. Seven patients had detrusor overactivity during urinary storage, which was easily evoked by abdominal straining such as cough manoeuvre and postural change. Four patients had low compliance detrusor, and three had detrusor overactivity and low compliance detrusor. Eight patients had a contractile detrusor on voiding. External sphincter EMG showed detrusor sphincter dyssynergia in three and unrelaxing sphincter in six patients. No uninhibited sphincter relaxation was found.

Of the patients in whom the urodynamic studies were made, nine (31\%) showed no evidence of detrusor overactivity, low compliance detrusor, or residual urine (pure form). All were female patients, mean age 52, range 18-70 years (table 2). Urethral pressure profilometry was performed on all nine patients; UPmax was decreased in four, mean value of $28 \mathrm{~cm} \mathrm{H}_{2} \mathrm{O}$, range $12-35 \mathrm{~cm} \mathrm{H}_{2} \mathrm{O}$. Water cystometry showed that two patients had incompetent urinary storage even at FDV, with no detrusor overactivity or uninhibited sphincter relaxation. The patients had neither urinary-vaginal fistula nor ectopic ureter. Two patients showed absence of a bulbocavernosus reflex, and one of voluntary sphincter contraction. Analysis of sphincter motor unit potential was performed in five patients, three of whom had high amplitude and polyphasic neurogenic changes. Two of the nine patients received 0.04 $\mathrm{mg} /$ day of oral clenbuterol for stress incontinence. One of them showed substantial improvement.

\section{Discussion}

The results showed stress induced urinary incontinence in 29 of $184(15.8 \%)$ patients, indicating that it is not a common urethrovesical symptom in spinocerebellar degeneration. However, it started with or after the occurrence of the disease and deteriorated gradually along with the other neurological signs, so that we could consider the symptom as a part of this disease.

Twenty of the 29 patients, including seven males, showed abnormal detrusor contraction or residual urine (complicated form). In these patients, abdominal straining could easily provoke detrusor overactivity, resembling the urge type of incontinence. Detrusor overactivity 
noted in these patients may correspond to lesions of white matter of the spinal cord, basal ganglia, and brainstem nuclei including the locus coeruleus in spinocerebellar degeneration. ${ }^{13}$ Mean volume of the residual urine in these patients was $169 \mathrm{ml}$, which tended to leak due to abdominal straining, resembling the overflow type of incontinence. Disturbed evacuation is commonly accompanied by low compliance detrusor or detrusor areflexia, which may reflect lesions of the sacral intermediolateral nucleus and the pelvic nerve in spinocerebellar degeneration. ${ }^{13}$

However, nine of the 29 patients showed no evidence of abnormal detrusor contraction or residual urine (pure form). Two of the nine patients showed incompetent urinary storage even at FDV, with no detrusor overactivity or anomalies of the lower urinary tract indicative of neurogenic sphincter dysfunction. The urethral continence mechanism against abdominal straining depends on two components: internal (smooth muscle) and external (striated muscle) sphincters. UPmax represents a total urethral closure pressure of various components. Low UPmax was noted in four of our patients, indicative of urethral weakness, which is considered as a factor even in genuine stress incontinence. ${ }^{1}$ Genuine stress incontinence is reported to occur through damage to the $\alpha$-adrenergic fibres innervating the internal sphincter ${ }^{14}{ }^{15}$; we could not investigate this matter in the present study. There is evidence of pudendal denervation of the external sphincter in patients with genuine stress incontinence associated with spina bifida occulta. ${ }^{4}$ Pudendal nerve blockade also affects stress relaxation of the urethral sphincter in female volunteers. ${ }^{16}$ We showed the absence of bulbocavernosus reflex in two and of voluntary sphincter contraction in one, and high amplitude and polyphasic neurogenic changes in three of five patients in whom the studies were made. Although we cannot completely exclude the influence of aging and delivery injury, our results show evidence of pudendal denervation, which can cause external sphincter weakness and may reflect lesion of the sacral Onuf's nucleus and the pudendal nerve in spinocerebellar degeneration. ${ }^{13}$ Two of the nine patients received $0.04 \mathrm{mg} /$ day clenbuterol, and one of them showed substantial improvement in the incontinence. Recent studies have shown that clenbuterol, a $\beta 2$-adrenergic agonist, improves genuine stress incontinence. ${ }^{17} \beta$-Agonists are thought to act on the striated urethral sphincter by stimulating adenylate cyclase release and increasing the cyclic AMP.$^{17}$ Clenbuterol seems to be beneficial also for incontinent patients with spinocerebellar degeneration, caused by pudendal nerve dysfunction. Finally, urodynamic studies are necessary to evaluate stress induced urinary incontinence in patients with spinocerebellar degeneration, to prescribe appropriate therapies.

1 Summitt RL, Bent AE. Genuine stress incontinence; an overview. In: Ostergard $\mathrm{DR}$, Bent $\mathrm{AE}$, eds. Urogynecology liams and Wilkins, 1991:393-403.

2 Haab F, Zimmern PE, Leach GE. Female stress incontinence due to intrinsic sphincter deficiency; recognition and management. F Urol 1996;156:3-17.

3 Snooks SJ, Setchell M, Swash M, et al. Injury to innervation of pelvic floor sphincter musculature in childbirth. Lancet of pelvic floor sphinc.

4 Fidas A, MacDonald HL, Elton RA, et al. Neurophysiological measurements in patients with genuine stress incontinence of urine and the relation of neurogenic defects to the presence of spina bifida occulta. Br f Urol 1988;62:46-50.

5 Leach GE, Farsail A, Kark P, Raz S. Urodynamic manifestations of cerebellar ataxia. $\mathcal{F}$ Urol 1982;128:348-50.

6 Sakakibara R, Hattori T, Tojo M, et al. Micturitional disturbance in hereditary spinocerebellar degeneration. Autonomic Nervous System (Tokyo) 1993;30:291-7. (In Japanese.)

7 Sakakibara R, Hattori T, Tojo M, et al. Micturitional disturbance in late cortical cerebellar atrophy. Autonomic Nervous System (Tokyo) 1992;29:575-579. (In Japanese.)

8 Beck RO, Betts CD, Fowler CJ. Genitourinary dysfunction in multiple system atrophy; clinical features and treatment in multiple system atrophy; clinical feat 62 cases. $\mathcal{F}$ Urol 1994;151:1336-41.

9 Sakakibara R, Hattori T, Tojo M, et al. Micturitional disturbance in multiple system atrophy. Fapanese fournal of Psychiatry and Neurology 1993;47:591-8. (In English.)

10 Hirayama K, Takayanagi T, Nakamura R, et al. Spinocerebellar degeneration in Japan; a nationwide epidemiological and clinical study. Acta Neurol Scand Suppl 1994;153:122

11 Siroky MB, Olsson CA, Krane RJ. The flow rate nomogram; 2 clinical correlation. $\mathcal{F}$ Urol 1980;123:208-10.

12 Abrams P, Blaivas JG, Stanton SL, et al. The standardization of terminology of lower urinary tract function; produced by the International Continence Society Committee on Standardization of Terminology. World $\mathcal{f}$ Urol 1989;6:23345.

13 Oppenheimer D. Neuropathology of autonomic failure. In: Bannister R, ed, Autonomic failure, 3rd ed. London; Oxford Bannister R, ed, Autonomic failure,

14 Srinivasan V, Blackford HN. Genuine stress incontinence induced by prazosin. Br F Urol 1993;72:510.

15 Light JK, Beric A, Petronic I. Detrusor function with lesions of the cauda equina, with special emphasis on the bladder neck. F Urol 199;149:539.

16 Thind P, Lose G, Colstrup H, et al. The effect of pharmacological stimulation and blockade of autonomic receptors and of pudendal blockade on urethral stress relaxation in healthy women. $\mathrm{Br} \mathcal{F}$ Urol 1994;74:86-92.

17 Yasuda K, Kawabe K, Takimoto Y, et al, and the Clenbuterol Clinical Research Group. A double-blind clinical trial of a $\beta 2$-adrenergic agonist in stress incontinence. International Urogynecology fournal 1993;4:146-51. 